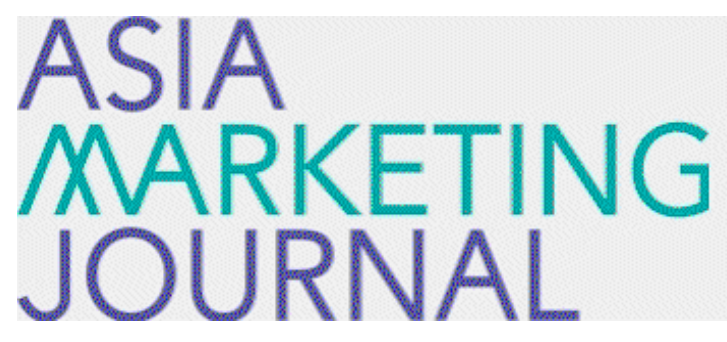

ASIA MARKETING JOURNAL

Volume 11 | Issue 2

Article 7

7-30-2009

\title{
Consumer Typology and Online Travel Websites
}

Hong Youl Ha

Felix Mavondo

Siva Muthaly

Follow this and additional works at: https://amj.kma.re.kr/journal

Part of the Marketing Commons

\section{Recommended Citation}

Ha, Hong Youl; Mavondo, Felix; and Muthaly, Siva (2009) "Consumer Typology and Online Travel Websites," Asia Marketing Journal: Vol. 11 : Iss. 2 , Article 7.

Available at: https://doi.org/10.53728/2765-6500.1239

This Article is brought to you for free and open access by Asia Marketing Journal. It has been accepted for inclusion in Asia Marketing Journal by an authorized editor of Asia Marketing Journal. 


\title{
Consumer Typology and Online Travel Websites: Heterogeneity between Taiwanese and Korean Young Adults Repurchasing Behavior*
}

\author{
Ha, Hong-Youl** \\ Felix Mavondo*** \\ Siva Muthaly****
}

This research attempts to investigate differences in past experiences of using internet in repurchasing. In doing so, the authors identify online consumer characteristics, particularly one-time and repeat users comparison across geographical borders of Korean and Taiwanese teenage customers. Results show that there are significant differences in online shopping typologies between Korean and Taiwanese customers. While attitude serves as a distinguishing factor for both data sets along the other two dimensions, trust does not. Since researchers have focused on comparisons between Western cultures and Asian cultures' online purchase behavior or Internet use, the current study provides a valuable comparison for this niche population of young customers at least in a Korean-Taiwanese context. The authors also make a brief argument that these findings can influence marketing practitioners and site developers in their strategies.

Key words: Consumer Typology, Cross-Cultural Study, Online Repurchasing

\section{Introduction}

One way in which the social sciences can contribute to the success of online tourism businesses is by providing a complete understanding of the decision making processes which online consumer heterogeneity is identified (Hyde, 2008). An appreciable amount of consumer research has investigated how online shopper typologies

\footnotetext{
This study was supported by Research Grant of the Institute of Management Research, Kangwon National University.

** Professor of Marketing, Kangwon National University, Chuncheon, South Korea(ha.h@kangwon.ac.kr), Corresponding Author

*** Professor of Marketing, Monash University, Melbourne, Australia(felix.mavondo@buseco.monash.edu.au)

**** Professor of Marketing, Swinburne University of Technology, Melbourne, Australia(smuthaly@swin.edu.au)
} 
influence internet usage (Kau, Tang, and Ghose 2003; Moe 2003; Rohm and Swaminathan 2004; Swaminathan., and Rao 1999). It is argued that prior literature has considered consumer typology differences across the customer vs. non-customer delineation (Andrews et al. 2007; Kim et al. 2006: Lian and Lin 2008), but that the distinction between repeat and one-time customers that have used an e-commerce site once versus those that repeatedly use the site has not been explored (e.g., Griffin 2002). A lack of consistency in the literature has resulted in an array of shopper typologies as not comparable (Ganesh, Reynolds, and Luckett 2007; Rohm and Swaminathan 2004). Thus, further investigation to advance knowledge in this area needs to focus on creating comparable online shopper typologies. This study makes an important contribution to the literature by extending knowledge of online shopper typologies.

A better understanding of shopper typologies plays a critical role in penetrating any markets. For example, an October 2006 survey by the publication Internet Retailer found that only a tiny percentage of US Internet retailers generate a majority of their foreign sales from this region (E-marketer 2007). In particular, South Korea and Taiwan play a key role in $\mathrm{e}^{-}$ commerce. Some simple statistics can illustrate this point: According to a 2007 ranking of 181 nations in the International Telecommunication Union Index (www.itu.int), South Korea is in the first place and Taiwan is in seventh place to reap the economic and social benefits on the internet. Despite the similarity between the two countries, South Korea shows extraordinary performance due to strongly promotinge-commerce in recent years, and is better than Taiwan in B2C revenues ( $Y u$ and Wang 2004). The prior work indicates that cross-cultural comparisons between the two countries are still needed to give a better understanding of online shopper typologies in different national cultural backgrounds. Thus, it is further argued that a comparison across Korean and Taiwanese respondents is important due to the high degree of $\mathrm{e}^{-}$ commerce use for both countries. It needs to also be reiterated that previous literature has only compared Korean characteristics against Western characteristics.

The objective of this study is to identify a new typology of online shoppers. Although few online shopper typologies have been developed for online store or service settings, there is a lack of research examining typologies, particularly in a repurchasing context. This issue is important for organizations as they should focus on their existing customers in novel ways to achieve optimum online business performance. To overcome this limitation, research needs to focus on online shopper typologies (repeat vs. one-time customers) that influence marketing strategies.

To this end, the current research examines the impact of customer typologies in a repurchasing context using a cross-cultural study. Specifically, the structure of this research is as follows. 
First, online shopper typologies are addressed. Second, research hypotheses, method, and results are outlined. Finally, the results are discussed, with limitations and further research directions presented.

\section{Conceptual Background}

\subsection{Online Consumer Characteristics}

Previous research has identified four determinants of online consumer typologies, namely personality traits, self-efficacy, demographic profiles, and acceptance of new IT applications (Lian and Lin 2008; Swaminathan, Lepkowska-White, and Rao 1999). These four factors are useful for predicting online purchasing behavior when researchers investigate the differences between online shoppers and non-shoppers.

Consumer typology has been updated over time. For example, Stone (1954) stated that shopping behavior has social-psychological origin and classified shoppers into four types: economic shopper, the personalizing shopper, the ethical shopper and the apathetic shopper. Stephenson and Willett (1969) identified consumers as recreational, convenience and price-oriented shoppers. Two additional categories namely psychosocializing and name-conscious shoppers were added by Moschis (1976). Bellenger and Kshoponkar (1980) suggest that consumers can be classified into recreational and convenience shoppers. Roy (1994) identified shopper typologies as frequent and non-frequent mall shoppers. In the context of online shopping, scholars would like to group consumers into tradition and online shoppers (Degeratu, Rangaswamy, and Wu 2001) or internet non-users and online buyers (Roy and Ghose 2005). Consumer groups are useful for identifying customers' propensity, particularly for entry-level companies, while the special characteristics of customer type, repeat and one-time customers, may be considered as a new typology of online consumer characteristics. Although customer types are identified customer segmentation, this characteristic is desirable because most B2C online companies are focusing on their existing customers. More importantly, there has been no research that has focused on comparisons between one-time and repeat customers, indicating a pressing need for researchers to investigate the dynamics inherent in such a categorization.

In this study, one-time customer is defined as an online customer who purchases just one time from an e-commerce website, while a repeat customer is defined as an online customer who purchased several times from the same $\mathrm{e}^{-}$ commerce website. More specifically, this study differentiates between a repeat customer who is loyal to a website and thus repeatedly purchasing from it. As compared with a onetime customer who searches for deals every time, but only happens to be buying from the 
same website just because it has the best offers. The two types of customer profiles are fundamentally different, as one-time customer will return on the basis of his/her best performance while repeat customer will make subsequent purchases.

Even though this study has established definitions of each group, we demonstrate how the proposed typology of one-time vs. repeat customers is different from that of non-loyal vs. loyal customers. In the context of $\mathrm{e}^{-}$ commerce, both non-loyal and one-time customers might be considered among the most price sensitive consumers, while the latter is more likely to revisit the same website than the non-loyal customers. Similarly, although in this study we identified repeat customers as loyal customers, they may be different from real loyal customers. Griffin (2002) points out that in developing any plan for upgrading repeat customers into loyal clients, marketers should understand how repeat customers turn into loyal clients. As the repeat customer stage is critical, Griffin (2002) suggests that providing key services increases the website customers' reluctance to switch to competitors-physically, economically, and psychologically.

\subsection{Potential Cultural Differences and Online Purchase Behaviors}

Since most researchers have focused on differences between individualist and collectivist societies, there may be a lack of research between collectivist societies. In this study South Korea and Taiwan were selected because they are two leading countries regarding the e-commerce industry and the online shopping and they share many similarities. According to ACNeilsen Global Consumer Attitudes towards Online Shopping Report(2005), for example, South Korea and Taiwan are in the fourth and seventh place respectively with at least $90 \%$ of internet users having made a purchase. As online shopping is prevalent in these two countries, one could postulate that there may be no significant differences in the level of online purchasing activity between collectivist societies at least in a Korean-Taiwanese context when they revisit websites to repurchase. Despite these figures, online shopping behavior may be greatly different between Korean and Taiwanese consumers. According to Hofstede's cultural dimensions (2003), for example, both Korea and Taiwan are slightly different on two aspects namely Uncertainty Avoidance (UAI: Korea 85 vs. Taiwan 64) and Long-Term Orientation (LTO: Korea 68 vs. Taiwan 82). However, South Korea's closest correlation with Taiwan in the Hofstede survey of 2003 was not discussed. Thus, these two countries are dissimilar allowing us to capture international differences, indicating that this study is able to provide insights into the micro-Asian diffusion of the e-commerce. However, if there were no significant cross-cultural differences in the 
〈Figure 1〉 Conceptual Research Framework

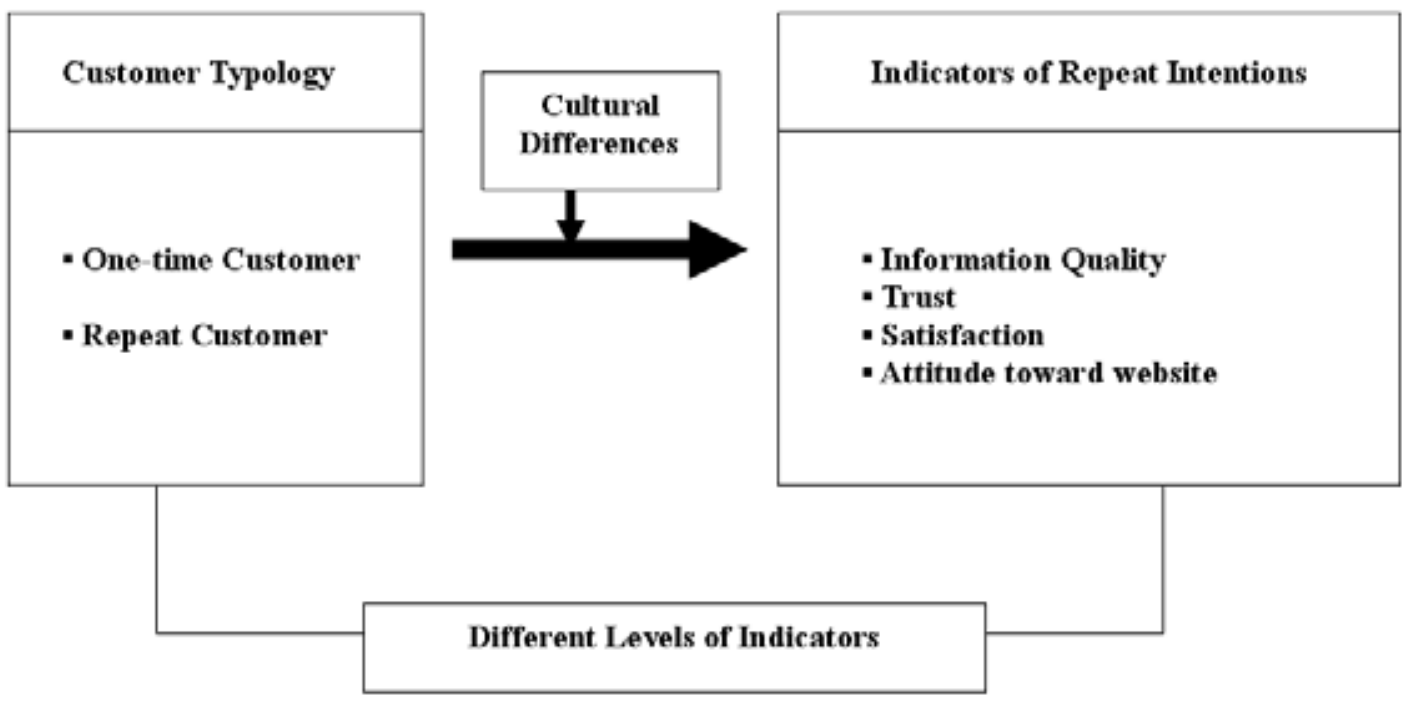

effects of information quality, satisfaction, trust, and attitude on repurchase intentions, one could argue that these hypothesized effects are robust across collectivist cultures.

In line with this observation, a conceptual framework by connecting the various constructs deal with in the current study is shown in $\langle$ Figure 1〉.

\section{Research Hypotheses}

This study assumes that current online shoppers may be different in their perceptions in respect of their future shopping intentions. In a repurchasing context, online consumers are likely to primarily depend on their past experience (Slyke et al. 2002) such as information quality, satisfaction, trust, and attitudes toward a particular website. Research shows that people tend to reconstruct their past experience as relatively consistent with their current behavior (Ross 1989).

Since such cues of past purchasing experiences as information quality, trust, satisfaction, and attitudes play a significant role in predicting online repurchase intentions, in this paper, we examine these variables as they have been identified by several scholars studying online purchasing behavior: information quality (Kim et al. 2007; Kuan et al. 2007; Li and Kirkup 2007; Vishwanath 2003), satisfaction (Mittal and Kamakura 2001; Yi and La 2004; Yoon 2002), trust (Doney and Cannon 1997; Flavián, Guinalíu, and Gurrea 2006; Harris and Goods 2004; Wolf 2000), and attitudes (Chau et al. 2002; Lee and Turban 2001; Li and Kirkup 2007; Teo et al. 2003; Yoh et al. 2003). 
Although these four constructs are related to each other at various theoretical levels, a number of studies have investigated relevant issues such as relationships between these constructs. Thus, this study only focuses on the differences in web purchasing behaviors of one-time and repeat teenager consumers using these four constructs in the Asian market.

As noted earlier, no significant difference was found between the consumers in Korea and Taiwan. This study proposes that there are other factors that may account for the difference in online shopping behavior between the two countries (e.g., Zhou et al. 2007). For example, the quality of information, consumer trust, satisfaction, and positive attitude towards the online shopping site are factors that can differentially influence purchase intentions of consumers from different countries (Lynch et al. 2001). Thus, a comparison of these factors is undertaken to address the question of whether differences in the antecedents of purchase intention explain differences in behaviors of online consumers (e.g., one-time vs. repeat purchase distinction).

\subsection{Information Quality and Consumer Typology}

A high level of information of online shopping is one of the driving forces when consumers revisit the website to shop. Along with the widespread adoption of the Technology Acceptance
Model (TAM) in information system research, perceived information has been used to explain consumer acceptance of online shopping (Pavlou 2003). In a repurchasing context, experience with online shopping is found to correlate positively with consumers' likelihood to shop online. However, existing consumers may have different approaches as to how to understand perceived information quality when they revisit the website. Although the internet offers the capability to deliver specific information tailored to the needs of the consumer (Hoffman and Novak 1996), the repeat customer may be more motivated by perceived information than the one-time customer. Evidence supports that customers who had less purchasing experience are often unable to evaluate all available informative cues while making purchase decisions (Gursoy and McCleary 2004; Häubl and Trifts 2000), indicating that there may be significant difference between repeat and one-time customer when they visit the website to purchase. Although the signaling theory demonstrates that customers infer information quality from the vendor's website, both new customers and repeat customers differently estimate the information (Kim, Xu, and Koh 2004). If the website had provided the same information to both customer groups, but if one-time customers estimated low-quality information, they are less likely to revisit the website to purchase than repeat customers. Their behavior is supported by the information processing approach, which focuses on memory 
and cognitive processing theory (Coupey, Irwin, and Payne, 1998). Thus, the following hypothesis is reached:

H1: Perceived information quality will discriminate between one-time customers and repeat customers illustrating that information quality will be positively evaluated by the latter group.

\subsection{Satisfaction and Consumer Typology}

Extant research conceptualizes customer satisfaction as a cumulative construct that is affected both by service expectations and performance perceptions in the current time period, as well as in prior time periods (Johnson, Anderson, and Fornell 1995). Although the marketing literature recognizes the importance of satisfaction, there is no general agreement on how the concept should be imfined (Rogers, Peyton, and Berl 1992). This lack of consensus implies that satisfaction may not mean the same thing to everyone (Oliver 1980). In this study we define e-satisfaction as the perceived degree of contentment with regard to a customer's prior purchase experience with a given electronic commerce firm (Anderson and Srinivasan 2003).

In many cases, the repeat customer intends to make a purchase and is not lacking any substantial information before making that decision. It indicates that frequent shopping may impact customer satisfaction. Arguments can be made for the discrimination between repeated customers and one-time customers on satisfaction. Supporting discrimination for repeat customers is the argument that if customers often purchase a service, favorable service judgments may continually lead to higher satisfaction. Supporting discrimination for one-time customers is the concept of expectation-performance. This is because one-time purchase behavior cannot be explained by post-purchase satisfaction/ dissatisfaction outcomes (Simintiras, Diamantopoulos, and Ferriday 1997). When customers revisit a service website, they start to treat the benefits of the service as a given and expect additional benefits from the service website (Shankar, Smith, and Rangaswamy 2003). The raised expectations may lead to lower satisfaction, indicating that there may be significant discrimination when both customers revisit the web to shop. More specifically, one-time customers are transactionspecific, whereas repeat customers are relationshipspecific, that is, overall satisfaction of repeat customers is the cumulative effect of a set of discrete service transactions with the website over a period of time (Oliver 1997; Rust and Oliver 1994). These arguments suggest the following hypothesis:

H2: Satisfaction with an e-commerce website is likely to be higher for repeat customers than for one-time customers. 


\subsection{Trust and Consumer Typology}

Since online trust fosters the development of e-commerce, it is important to investigate differences between repeat customers and onetime customers. Within the compact e-commerce domain of research, trust has been defined as a willingness to believe, or an individual's beliefs, regarding various attributes of the other party (McKnight and Chervany 2002). Since conceptualization of trust may vary subtly in its focus, this study conceptualizes online trust as the belief that the behavior of an online vender is dependable(Chauetal.2007).

There is agreement on conditions that must exist for trust development. Trust is vital in an uncertain and risky environment, while it would not be needed if actions could be undertaken with complete certainty and no risk (GrabnerKraeuter, 2002, p. 44). Prior research that investigates customers' trust in an online provider purposefully differentiates the trust perceived or developed through different types of visits to a retailer's website (Kim, Ferrin, and Rao 2006). For example, new customers who interact with a particular website for the first time will make strong inferences about the attributes of the vendor from what they first experience at the website. However, repeat customers may interpret information available at the website to determine the vendor's intentions and infer its trustworthiness (Kim et al. 2004).

From this observation it can be argued that there are different levels of trust between repeat customers and one-time customers on trust. For repeat customers it is argued that if customers often visit a specific website, beliefs about website services may continually lead to higher trust. For the one-time customers it is the social-psychological perspective that appears to be most relevant for understanding consumer trust in online shopping. When one-time customers visit a particular website, they are likely to avoid the harm of an undesirable outcome that may be greater than the benefits of a successful outcome (Lee and Turban 2001). The raised uncertainty may lead to lower trust. These arguments suggest the following hypothesis:

H3: There will be differences in the level of trust in an e-commerce website, as repeat purchasers will be more trusting than one-time buyers.

\subsection{Attitudes and Consumer Typology}

Generally, attitude is defined as "a psychological tendency that is expressed by evaluating a particular entity with some degree of favor or disfavor" (Eagly and Chaiken 1993, p.1). Attitudes are considered as a summary of hypothetical constructs representing overall feelings towards or evaluative judgments about a person, object or issue (Zajonc and Markus 1982). This study conceptualizes attitude as overall feelings towards a particular website with some degree of favor. 
In the e-commerce context, a number of previous studies showed that attitudes toward the website shopping were positively related to online shopping intention (e.g., Shim et al. 2001). However, attitude toward the website shopping in a repurchasing context may be dependent on consumer typology. This attitude is inferred only when stimuli denoting an attitude object are observed to elicit responses expressing a given degree of evaluation (Eagly and Chaiken 1993). Arguments can be made for the differences in attitudes towards $\mathrm{e}^{-}$ commerce website between repeat customers and one-time customers. If repeat customers often navigate a particular website, favorable evaluation may lead to positive attitudes. The situation is different for one time visitors. Because one-time purchase behavior is generally a function of many factors in addition to a seemingly relevant attitude toward online shopping (Eagly and Chaiken 1993), such behavior is limited to explain one-time customers' attitudes toward online shopping with a particular website. As one-time customers do not have sufficient shopping experience with a particular website, they may adjust their attitudes when they revisit the website. If their attitudes toward online shopping have not been established, it indicates that there may be significant discrimination when both customers visit the web to shop. There is evidence to suggest that consumer attitudes toward online shopping are different across consumer groups (Sorce, Perotti, and
Widrick 2005). These arguments suggest the final hypothesis:

H4: There are significant differences in attitude towards online shopping between one-time customers and repeat customers with repeat customers having a more favourable attitude than one-time purchasers for the specific e-commerce website.

\section{Methodology}

In terms of cross-cultural study, there are more than 2,000 travel agencies in Taiwan, and the Tourism Bureau of Taiwan (2007) shows that online travel industry in Taiwan is one of the top shopping areas. Since an increasing number of online consumers are using online travel agencies (Wang and Cheung 2004), Taiwan provides an appropriate empirical setting for investigating online consumer purchase behavior. These trends are also similar in Korea (Yoon, Yoon, and Yang 2006). Two particular countries were chosen because they provide a considerable degree of variety in terms of online shopping conditions related to economic and social circumstances (e.g., Albert, Yoshida, and van Opstal 1998). Therefore, the selection of travel industry is useful for a better understanding of consumer repurchase behavior. 


\subsection{Sample Selection}

In order to guard against possible sample selection bias, cross-cultural research usually requires comparable samples which involve drawing matched samples from identifiable subgroups of the population like housewives and students (Madden, Hewett, and Roth 2000). Based on this reasoning student samples were collected from Korea and Taiwan because they were actual users and/or consumers of at least online service categories, particularly in the travel services. Although teenagers' shopping behavior and the purchased items can be different from adults', the nature of the current study was to understand young consumers' shopping behavior, particularly from two different shopping typologies. In this regard, Christou and Kassianidis (2003) pointed out that a better understanding of young consumers' behavior is important for capturing their perceptions of the relevant advantage and compatibility of online travel shopping.

All research data were obtained by trained instructors in the two countries. The questionnaire was sent to 612 subjects by two researchers in
Korea $(\mathrm{n}=348)$ and Taiwan $(\mathrm{n}=264)$. It took four weeks to complete the data collection. After several follow-up procedures (e.g., repeated reconfirm instruction), we obtained responses from 590 respondents (334 in Korea and 256 in Taiwan). Due to missing data, a total of 499 usable questionnaires were obtained (284 in the Korean sample giving a response rate of $82 \%$ and 215 in the Taiwanese sample for a response rate of $81 \%$ ).

Of the total sample 63 percent were males $(\mathrm{n}=179)$ and 37 percent were female $(\mathrm{n}=105)$ for the Korean sample, whereas it was 62 percent males $(\mathrm{n}=133)$ and 38 percent were female $(n=82)$ for the Taiwanese sample. Thus, gender balance was comparable for the two samples (please see $\langle$ Table 1)). A total of 57 percent of the Korean sample were one-time customers ( $\mathrm{n}=162)$ and 43 percept were repeat customers $(n=122)$, whereas a total of 33 percent of the Taiwanese sample were onetime customers $(\mathrm{n}=71)$ and 67 percept were repeat customers $(n=144)$.

As outlined by Wang and Waller (2006), the decision to use university students as a subject population was motivated by considerations of

$\langle$ Table 1〉 Respondent Types between Korean and Taiwanese consumers

\begin{tabular}{lcc}
\hline & Korean Sample $(\mathrm{n}=284)$ & Taiwanese Sample $(\mathrm{n}=215)$ \\
\hline Male & $179(63 \%)$ & $133(62 \%)$ \\
Female & $105(37 \%)$ & $82(38 \%)$ \\
One-time customer & $162(57 \%)$ & $71(33 \%)$ \\
Repeat customer & $122(43 \%)$ & $144(67 \%)$ \\
\hline
\end{tabular}


ease of recruitment and administration, as well as the desire to maximize the equivalence of the sample across the two countries. Although there may be different social cultures, students are relatively homogeneous in terms of such socioeconomic and demographic characteristics such as age, income, education, and social status (Peterson, 2001; Wang and Waller, 2006). Given that the main objective of the study was to examine the nature of different online consumer purchase behaviors within a theoretical framework, homogeneous samples were desirable.

\subsection{Assessment of the Measurement}

One inherent difficulty in conducting crosscultural research is showing evidence of measurement equivalence (Brady and Robertson, 2001). Measurement equivalence pertains to whether the variables and items used in the questionnaire are comparable across Korea and Taiwan. Steenkamp and Ter Hofstede (2002) identify three related areas: 1) translation: 2) calibration: and 3) metric equivalence.

Since language and meanings are generally context-specific and culture-bound, well-written translation is the key to any cross-cultural research. A back translation method was used to develop Korean and Taiwanese versions. The original English questionnaire was translated into the Korean language by two persons bilingual in Korean and English. The Taiwanese version was also translated by two persons bilingual in
Taiwanese and English. After initial drafts were developed, careful review processes were conducted comparing each draft and discussing its clarity and the comprehensibility of the questions.

Calibration equivalence refers to how the units of measurement are used across populations. This is achieved by using identical units of measurement or accurate conversion of different scales of measurement. Both the Korean and Taiwanese questionnaires were composed of the Web-usage-related items, online shopping items, and demographics. Some of demographic questions posed a problem since they are classified in a different way in both countries (Brengman et al. 2005). Therefore these questions were rescaled to broad categories. The education measure, for example, was revised to correspond to the norms of the two countries, where diploma indicates a higher qualification than secondary school. Because data were collected from university students in Korea and Taiwan, the education question used commonly requiring conversion (year 1 to year 4). Furthermore, Richins and Dawson (1992) used a five-point Likert scale to collect their original data to insure calibration equivalence. In the current study, the same care was given to translation of the scale point labels because university students in each country are familiar with Likert response scales.

Metric equivalence can be examined after the data have been collected. Metric equivalence 
is best assessed through confirmatory factor analysis (Mullen 1995; Steekamp and Baumgartner 1998: Vandenburg and Lance 2000). Steekamp and Baumgartner (1998) referred to metric equivalence as measurement invariance and identified six forms of measurement invariance: 1) configural invariance: 2) metric invariance: 3) scalar invariance: 4) factor covariance invariance: 5) factor variance invariance: and 6) error variance invariance. While the first three forms of measurement invariance tests represent nested models in the sense that each test is nested in the one that precedes it, the order of the last three forms of measurement invariance tests is arbitrary and depends on the research objectives (Wang and Waller 2006).

In testing equivalence across two or more groups, the recommended procedure is to verify metric equivalence (Mullen 1995). Metric equivalence is best assessed through confirmatory factor analysis (Mullen 1995; Steenkamp and Baumgartner 1998). As the purpose of the present research is to test the cultural differences of online shopping behavior, the construct measures have to exhibit at least partial scalar invariance across the two countries (Steenkamp and Baumgartner
1998). Without evidence of at least partial scalar invariance, comparing construct or factor means across countries is meaningless (Wang and Waller 2006). RMSEA for the configural invariance model (the first level of measurement invariance) across the countries was greater than 0.05 indicating a good fit. As shown in Table 2, the two incremental fit indices were also above the commonly recommend 0.9 level (TLI $=.91$, CFI $=0.92)$. The normed chisquare $\left(X^{2} / \mathrm{df}\right)$ was 2.586 , below the recommended cut-off point of 3 . These results, coupled with the fact that all factor loadings were highly significant in both countries, suggest that the construct measures exhibited adequate configural invariance across the countries. Also, it should be noted that the $x^{2}$ value for the configural invariance model is the sum of the $x^{2}$ values obtained for the two sub-samples (South Korea and Taiwan). After the configural invariance model was established, the final test was to compare the configural invariance model and the partial scalar invariance model. The chisquare difference test was not significant $\left(\Delta X^{2}\right.$ $(12)=19.415, \mathrm{p}>.05)$ and the other fit indices were either close or slightly better. Thus, we

$\langle$ Table 2〉 Assessment of Measurement Invariance and Latent Mean Difference in the Korea and Taiwan

\begin{tabular}{|c|c|c|c|c|c|c|c|c|}
\hline ecification & $X^{2}(d f)$ & $\begin{array}{c}\text { Model } \\
\text { Compared }\end{array}$ & $\Delta x^{2}$ & $\mathrm{p}$-Value & RMSEA & TLI & $\mathrm{CFI}$ & $x^{2} / d f$ \\
\hline & 75 & N/A & $\mathrm{N} / \mathrm{A}$ & N/A & .069 & .91 & .92 & 2.586 \\
\hline Full & 76 & M2 vs. M1 & 13.809 & .01 & 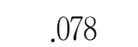 & .87 & .89 & 2.598 \\
\hline Partial scalar invariance model (M3) & $774.814(302)$ & M3 vs. M1 & 19.415 & . 047 & .065 & .91 & .93 & 2.565 \\
\hline
\end{tabular}


can conclude that partial scalar invariance has been achieved across the samples.

\subsection{Measures}

The four constructs were measured by nineteen questions using a five-point Likert scale ( $1=$ strongly agree and $5=$ strongly disagree) adapted from published scales (see 〈Table 1〉). These four factors of online past experience measured were the following: information quality, with seven items adapted from Srinivasan et al. (2002); satisfaction, with four items adapted from Anderson and Srinivasan (2003); trust, with five items adapted from Flavián et al. (2006); and, positive attitude, with five items adapted from Simon and Peppas (2005) (see Appendix).

\subsection{Criteria for Defining the Sample}

It might be expected that student buying behavior would vary by country, but a previous research studying Australian, English, and American students concludes that "only a relatively small number of attitudes and opinions regarding e-commerce result in differences between purchasers and non-purchasers (Teach and Schwartz 2003, p. 134)." Based on this evidence, the main criteria for selecting participants for the sample in this study was that they should have had a minimum of six months experiences shopping on a specific website with at least one travel-related purchase within that period. To avoid confusions that would severely undermine the validity of the empirical findings, respondents were carefully asked to consider a particular website where they had purchased travel-related purchase (e.g., airline ticket, accommodation booking, rental car, and travel package).

\subsection{Non-response Bias}

We have checked for non-response bias between the two periods. Non-response bias was examined using the method proposed by Armstrong and Overton (1977). One viable check for non-response bias is to split the sample into early $(n=212$ for the Korean sample and $\mathrm{n}=114$ for the Taiwanese sample) and late respondents $(\mathrm{n}=72$ for the Korean sample and $n=101$ for the Taiwanese sample). No significant differences between early and late respondents in the two countries were found on any of the variables of interest in this study, which lead us to conclude that nonresponse bias in this study was not a serious problem. The high response rate (over $80 \%$ in both countries) provides further support for this conclusion.

\subsection{Reliability and Validity}

As shown in 〈Table 3$\rangle$, reliability analyses confirmed that these four factors had acceptable 
〈Table 3〉 Final Rotated Factor Matrix and Cronbach's Alpha Scores: Korea and Taiwan

\begin{tabular}{|c|c|c|c|c|c|c|c|c|c|c|}
\hline & \multicolumn{2}{|c|}{1} & \multicolumn{2}{|r|}{2} & \multicolumn{2}{|r|}{3} & \multicolumn{2}{|r|}{4} & \multicolumn{2}{|c|}{ Reliability } \\
\hline & Korea & Taiwan & Korea & Taiwan & Korea & Taiwan & Korea & Taiwan & Korea & Taiwan \\
\hline Information Quality 1 & .693 & .597 & & & & & & & .761 & .853 \\
\hline Information Quality 2 & .694 & .512 & & & & & & & & \\
\hline Information Quality 3 & .599 & .568 & & & & & & & & \\
\hline Information Quality 4 & .594 & .559 & & & & & & & & \\
\hline Information Quality 5 & .738 & .501 & & & & & & & & \\
\hline Satisfaction 1 & & & .705 & .656 & & & & & .870 & .876 \\
\hline Satisfaction 2 & & & .767 & .820 & & & & & & \\
\hline Satisfaction 3 & & & .699 & .739 & & & & & & \\
\hline Satisfaction 4 & & & .706 & .665 & & & & & & \\
\hline Trust 1 & & & & & .507 & .523 & & & .788 & .862 \\
\hline Trust 2 & & & & & .535 & .627 & & & & \\
\hline Trust 3 & & & & & .527 & .656 & & & & \\
\hline Trust 4 & & & & & .667 & .683 & & & & \\
\hline Trust 5 & & & & & .619 & .697 & & & & \\
\hline Attitudes 1 & & & & & & & .572 & .682 & .822 & .903 \\
\hline Attitudes 2 & & & & & & & .654 & .720 & & \\
\hline Attitudes 3 & & & & & & & .551 & .783 & & \\
\hline Attitudes 4 & & & & & & & .599 & .685 & & \\
\hline Attitudes 5 & & & & & & & .551 & .730 & & \\
\hline
\end{tabular}

Note: ( ) is scores for the Taiwanese Data.

psychometric properties. Factor analysis with VARIMAX rotation was used to assess the discriminant and convergent validity. The threshold of factor loading is 0.5. Based on the above criteria, two of the seven items used to measure information quality were eliminated. That is, 5 items were retained for an overall score for information quality. 〈Table 3〉 illustrates the results and shows that most of the constructs have acceptable validity.

The resulting five factor solution accounted for 69 percent of the variance. All items loaded cleanly on their identified factors. These items were re-analyzed using split samples of males and females and one-time purchasers and repeated purchasers but still loaded on the same factors for each group. If one has already tested for measure equivalence there is no point in going back to EFA. The same model should be used for convergent and discriminant validity by calculating AVE, and comparing the covariances of latent variables. 


\section{Results}

The variables underlying in this study are used in a two-group discriminant analysis (Hair et al. 1998) to determine whether meaningful differences exist between the identified groups and to determine the discriminating power of each significant variable. The second stage in the analysis is to evaluate the predictive validity of the theory (Andrews et al. 2007). This procedure is processed through the classification statistics that compares actual versus predicted classification of the respondents in the study using cross-validation. The individual cases are classified into a group according to the classification functions computed from all the data except the case being classified (Huberty 1994). Percentages of correct classification vary across research context, but it is recommended that it should be at least one quarter than that achieved by chance (Hair et al. 1998).

\subsection{Discriminating between One-time and Repeat Customers}

To permit us to examine which past experience discriminates repeat customers from one-time customers from each country, the variable was one-time customers $=1$ and repeat customers $=2$. For the Korean data the findings showed that information quality (Wilk's $\lambda=.908$. $\mathrm{p}<0.01$ ), satisfaction(Wilk's $\lambda=.943 . \quad \mathrm{p}<0.05$ ), and attitudes (Wilk's $\lambda=.956$. p<0.01) were significant in discriminating between one-time customers and repeat customers. On the one hand, the findings for the Taiwanese data showed that attitudes (Wilk's $\lambda=.919 . p<0.05$ ) was the only significant variable.

The predictive validity of the classification of one-time customers and repeat customers shows that 68.9 (67.5, Taiwanese data) percent of the selected original grouped cases and 66.7 (64.9, Taiwanese data) percent of the selected cross-validated grouped cases were correctly classified (see 〈Table 4〉).

As the result (Wilk's lambda) is a very simple approach to test the correlation between two variables, the results may lack the explanatory and/or predictive power to explain the online purchase behavior. Thus, hypotheses were tested with one-way ANOVA, with Scheffé test to examine whether there were differences in the four kinds of online shopping factors between repeat customers and one-time customers.

The data fully support the result of Wilk's lambda. A consistent pattern was found in both samples: repeat customers' attitudes toward the website shopping were more favorable than one-time customers. It is noticeable that the scores for attitudes toward the web shopping were lower than 2.50 for repeat customers in both samples, indicating that positive attitudes were significantly desirable when they revisit the website to shop.

To summarize, we tested hypotheses whether 
〈Table 4〉 Difference in Past Experience between One-time and Repeat Customers: Korea and Taiwan

\begin{tabular}{|c|c|c|c|c|c|c|}
\hline Attributes & Wilk's $\lambda$ & F-ratio & Sig. & Correlations & $\begin{array}{l}\text { Canonical Discriminar } \\
\text { One-time and Repeat }\end{array}$ & $\begin{array}{l}\text { nt Means } \\
\text { Customers }\end{array}$ \\
\hline \multicolumn{7}{|l|}{ Korean Data } \\
\hline Information Quality & .908 & 15.676 & .008 & .399 & 0.24 & 0.42 \\
\hline Satisfaction & .943 & 9.484 & .049 & .238 & 0.18 & 0.32 \\
\hline Trust & .978 & 3.644 & .602 & .149 & 0.11 & 0.20 \\
\hline Attitudes & .956 & 7.513 & .007 & .326 & 0.21 & 0.37 \\
\hline \multicolumn{7}{|c|}{ Percentage Correctly Classified } \\
\hline \multicolumn{7}{|c|}{ Selected original grouped cases (\%) 69.9} \\
\hline \multicolumn{2}{|c|}{ Cross validated grouped cases (\%) } & 66.9 & & & & \\
\hline \multicolumn{7}{|l|}{ Taiwanese Data } \\
\hline Information Quality & .954 & 5.105 & .403 & .187 & 0.28 & 0.17 \\
\hline Satisfaction & .957 & 4.803 & .308 & .207 & 0.27 & 0.16 \\
\hline Trust & .910 & 10.352 & .066 & .300 & 0.41 & 0.24 \\
\hline Attitudes & .919 & 9.287 & .048 & .285 & 0.39 & 0.23 \\
\hline \multicolumn{7}{|c|}{ Percentage Correctly Classified } \\
\hline \multicolumn{3}{|c|}{ Selected original grouped cases (\%) 67.5} & & & & \\
\hline \multicolumn{2}{|c|}{ Cross validated grouped cases (\%) } & 64.9 & & & & \\
\hline
\end{tabular}

past experience provides a better understanding of online repurchasing behavior which can design marketing strategy in using the website for purchasing. $\mathrm{H} 1$ and $\mathrm{H} 2$ are supported as information quality and satisfaction discriminate between one-time customers and repeated customers for the Korean data, while two variables are not supported in the Taiwanese data. H3 that Trust will discriminate between one-time customers and repeat customers who choose to use the website for repurchasing is not significant in both samples. However, H4 is strongly supported as attitudes discriminate between one-time customers and repeat customers in both samples.

\subsection{Post-hoc Justification}

As shown in 〈Table 5〉, we were able to establish that the measurement model for the constructs used in this study, there were no significant differences across the samples for Taiwan and Korea. This allows us to compare the different findings with some confidence. The hypothesis for information quality is 
$\langle$ Table 5$\rangle$ Results of four factors by online consumer typology

\begin{tabular}{lcccccc}
\hline & $\begin{array}{c}\text { One-time } \\
\text { Customer }\end{array}$ & $\begin{array}{c}\text { Repeated } \\
\text { Customer }\end{array}$ & $\begin{array}{c}\text { Regular Customer } \\
\text { (one-time+repeated) }\end{array}$ & F-value & P-value & Hypothesis \\
\hline Korean Data & & & & & & \\
Information Quality & 2.45 & 2.25 & 2.38 & 6.20 & .002 & H1: Supported \\
Satisfaction & 2.69 & 2.43 & 2.59 & 3.04 & .048 & H2: Supported \\
Trust & 2.82 & 2.75 & 2.80 & 0.27 & N.S & H3: Not Supported \\
Attitudes & 2.71 & 2.49 & 2.62 & 3.68 & .026 & H4: Supported \\
& & & & & & \\
Taiwanese Data & & & & & & \\
Information Quality & 2.45 & 2.33 & 2.38 & 0.32 & N.S & H1: Not Supported \\
Satisfaction & 2.57 & 2.63 & 2.67 & 0.17 & N.S & H2: Not Supported \\
Trust & 2.57 & 2.50 & 2.53 & 0.12 & N.S & H3: Not Supported \\
Attitudes & 2.67 & 2.19 & 2.37 & 5.46 & .020 & H4: Supported \\
\hline
\end{tabular}

Note: $1=$ strongly agree, $5=$ strongly disagree.

supported for the Korean sample but not for the Taiwan sample. This suggests that information quality is far more important in Korea as a differentiator among one-time, repeat and regular customers than in Taiwan. The same conclusion is arrived at with respect to the degree of satisfaction. However, the ability of the website to evoke trust is important for both countries and without this successful interaction online would be severely limited in both countries. The common similarity across these two cultures is the attitudes to online shopping. Thus, the predisposition to online shopping is different across the different customer groups in both cultures. While the means across the countries are roughly comparable there is evidence of differences in findings across cultures.

\section{Discussion}

This study shows that Korean and Taiwanese teenage customers have significant differences in their past experience of online shopping in using the website for repurchasing. Taiwanese young customer typologies are discriminated only by attitudes toward the website shopping, but there are no significant differences in customer trust between the two countries. In a recent study by Park and Jun (2003), they demonstrated the insignificant difference in online buying experience between Korean and American consumers, however this study shows that there are significant differences at least in a Korea-Taiwan context. Since researchers 
have focused on comparisons between Western cultures and Asian cultures on online purchase behavior or Internet use (Andrews et al. 2007; Chau et al. 2002; Kuan et al. 2007; Li and Kirkup 2007: Park and Jun 2003), the current study provides a valuable comparison for this niche population of young customers across Asian borders.

The current study significantly discriminates differences between one-time customers and repeat customers to use the website for repurchasing. Korean repeat customers are discriminated by information quality, satisfaction, and attitudes, while Taiwanese repeat customers are discriminated only by attitudes. This study shows that Korean and Taiwanese repeat customers have differences in their online shopping behavior. These differences are directly attributable to the different stages of online purchase processes. Since Korea has the top position in the world in terms of $\mathrm{e}^{-}$ commerce site access with 78.2 percent of its internet users visiting e-commerce sites (Park and Jun 2003), Korean repeat customers are more willing to accept their beliefs about prior experience than Taiwanese customers. On the one hand, one possible reason that Taiwanese repeat customers are discriminated only by attitudes is that they may have the hesitation about the conviction to return or switch. This may be a possible way as to why attitudes toward a particular website are an important factor for Taiwanese repeat customers.

Repeated shopping behavior should occur to shoppers who hold a higher trust to the website, not lower, but interestingly, there are no significant differences in online trust between one-time customers and repeat customers in both data, indicating that both customer groups have similar perceptions about their beliefs. While a general common sense suggests that perceived trust levels of an existing customer are different from other customer types (Chau et al. 2007; Kim et al. 2006; Singh and Sirdeshumkh 2000), the present study shows that there is no significant difference between the two typologies at least a Korean-Taiwnese context. Although customers between the two countries are identified by uncertainty avoidance, one possible explanation may be that two cultural groups are characterized as high uncertainty avoidance (Hofstede 2003), indicating that they are less open on their ongoing shopping activity. Thus, the present study contributes to the literature that existing customers' trust in an online provider does not purposefully differentiate the trust perceived through different types of visits to the website, particularly in a repurchasing context.

From the findings, a direct comparison between prior studies' results and current results would have on existing theory in the area needs to be explicitly clear. In terms of $\mathrm{H} 3$, both frequent and non-frequent online shoppers are not distinguished by online shopping trust issue because online trust increases on the basis of experience (Swaminathan et al. 1999). The 
current study also highlights the indifference of online shopping trust between two typologies. On the other hand, prior studies identify the difference between browsers and buyers to understand information quality (Hoffman and Novak 1996: Moe 2003), while there is no difference between one-time and repeat customers in a Taiwanese context even though the shoppers are driven by different motivations. The comparisons suggest that customers who are distinguished by information quality are likely to shop online for specific types of information.

\subsection{Managerial Implications}

Online travel practitioners need a better understanding of online customer typologies, particularly one-time customers and repeat customers. Since they emphasize the importance of their existing customer, our new typology, one-time customers and repeat customers, provides valuable implications when one-time customers particularly return to buy. One possible guide is that practitioners could focus on developing customer strategies for generating trust beliefs. Since this study provides evidence that there are no significant differences in online trust between one-time customers and repeat customer in both countries, trust-oriented marketing strategeis (e.g., personalized services) may achieve better performance from both customers in Asian borders. Generally, online trust is useful for facilitating customer motivations because marketing practitioners seem to be increasingly realizing the value of communicating with their existing customers via the web (Roy and Ghose 2005). Trust-oriented marketing communication can aid marketing practitioners in their efforts to develop effective online trust strategies for travel organizations in a Korean-Taiwanese context. In so doing, judicious marketing practitioners will also remember the importance of consumer attitude toward their website. Thus, we suggest that a complete understanding of the direction of each of the four variables is essential for reinforcing their online competitiveness.

\subsection{Limitations and Further Research}

This study has some limitations owing to its exploratory stage, and set the future agenda for research in this area. First, this study uses the student sample, which restricts the results from being generalized to other populations. Although student samples are prevalent in consumer behavior research (e.g., Holbrook and Gardner 2000; Martin 2003) they can lessen external validity. However, given a series of procedures that assessed the measurement from a cross-cultural perspective, the current study was deemed appropriate. Nevertheless, further research is encouraged to generalize our findings. Another issue for further research is to establish a theoretical formation of customer typology between one-time customers and repeat customers. This study identified these customer characteristics 
as one of online consumer typologies, but further research can be addressed with scientific evidence. Finally, further study should be compared in a broader context against the set of other geographically specific studies such as those focusing on Western customers in order to broaden categorization of customer profiles across the globe.

〈received: 2009. 04. 18〉

〈accepted: 2009. 05. 10〉

\section{References}

ACNeilsen (2005, October). Global Consumer Attitudes towards Online Shopping Report, Availableat: http://us.acnielsen.com/pubs/ 2005_q4_ci_online.shtml

Akhter, Syed H. (2003), "Digital Divide and Purchase Intention: Why Demographic Psychology Matters," Journal of Economic Psychology, 24(3), 321-327.

Albert, M.B., P.C. Yoshida, and D. van Opstal (1998), "The New Innovators: Global Patenting Trends in Five Sectors," US Department of Commerce.

Anderson, Rolph E. and Srini S. Srinivasan (2003), "E-satisfaction and E-loyalty: A Contingency Framework," Psychology \& Marketing, 20(2), 123-138.

Andrews, Lynda., Geoffrey Kiel, Judy Drennan, Maree V. Boyle, and Jay Weerawardena
(2007), "Gendered Perceptions of Experiential Value in Using Web-based Retail Channels," European Journal of Marketing; 41(5/6), 640-658.

Armstrong, J. Scott and Terry S. Overton (1977), "Estimating Non-response Bias in Mail Survey," Journal of Marketing Research, 14(3), 396-402.

Bellenger, D.N. and P.K. Kargaonkar (1980), "Profiling the Recreational Shopper," Journal of Retailing, 56(3), 77-82.

Brady, Michael K. and Christopher J.Robertson (2001), "Searching for a Consensus on the Antecedent Role of Service Quality and Satisfaction: An Exploratory Cross-national Study, Journal of Business Research, 51 (1), 53-60.

Brengman, Malaika., Maggie Geuens, Bert Weijters, Scott M. Smith, and William R. Swinyard (2005), "Segmenting Internet Shoppers based on Their Web-Usage-Related Lifestyle: A Cross-cultural Validation," Journal of Business Research, 58(1), 79-88.

Chau, P.Y.K., M. Cole, Anne P. Massey, Mitzi M. Montoya-Weiss, and P.M. O’Keefe (2002), "Cultural Differences in the Online Behavior of Consumers," Communications of the ACM, 45(10), 138-143.

Chau, Patrick., Paul J. Hu, Bill L.P. Lee, and Anson K.K. Au (2007), "Examining Customers' Trust in Online Vendors and Their Dropout Decisions: An Empirical Study," Electronic Commerce Research and App- 
lication, 6(2), 171-182.

Childers, Terry L., Christopher L.Carr, Joann

Peck, and StephenCarson (2001), "Hedonic

and Utilitarian Motivations for Online

Retail Shopping Behavior," Journal of Retailing, 77(4), 511-535.

Christou, Evangelos and Panagiotis Kassianidis

(2003), "Consumer's Perceptions and Adoption of Online Buying for Travel Products," Journal of Travel \& Tourism Marketing, 12(4), 93-107.

Coupey, Eloïse., Julie R. Irwin, and John W. Payne (1998), "Product Category Familiarity and Preference Construction," Journal of Consumer Research, 24(March), 459-468.

Degeratu, A.M., A. Rangaswamy, and J. Wu (2001), "Consumer Choice Behavior in Online and Traditional Supermarkets: The Effects of Brand Name, Price and Other Search Attributes," International Journal of Research in Marketing, 17(1), 55-78.

Dittmar, Helga., Karen Long, and Rosie Meek (2004), "Buying on the Internet: Gender Differences in On-line and Conventional Buying Motivations," Sex Roles, 50(5/6), 423-444.

Doney, Patricia M. and Joseph P. Cannon (1997), "An Examination of the Nature of Trust in Buyer-Seller Relationships," Journal of Marketing, 61(2), 35-51.

E-marketer (2007), "Asia-Pacific B2C e-commerce," [available at: http://www.emarketer.com/ Reports/All/Em_b2c_ecom_asia_feb07]
Eagly, Alice H. (1995), "The Science and Politics of Comparing Women and Men," American Psychologist, 50(3), 145-158.

Eagly, Alice H. and Chaiken, S. (1993), The Psychology of Attitudes, FortWorth: Harcourt Brace Jovanovich, TX.

Eastlick, Mary Ann., Sherry L.Lotz, and Patricia Warrington (2006), “Understanding Online B-to-C Relationships: An Integrated Model of Privacy Concerns, Trust, and Commitment," Journal of Business Research, 59 (8), 877-886.

Flavián, Carlos., Miguel Guinalíu, and Raquel Gurrea (2006), "The Role played by Perceived Usability, Satisfaction and Consumer Trust on Website Loyalty," Information \& Management, 43(1), 1-14.

Ganesh, Jaishankar., Kristy E. Reynolds, and Michael G. Luckett (2007), "Retail Patronage Behavior and Shopper Typologies: A Replication and Extension Using a Multiformat, Multi-method Approach," Journal of the Academy of Marketing Science, 35(3), 369-381.

Girard, Tulay., Pradeep Korgaonkar, and Ronnie Silverblatt (2003), "Relationship of Type of Product, Shopping Orientations, and Demographics with Preference for Shopping on the Internet," Journal of Business \& Psychology, 18(1), 101-120.

Grabner-Kraeuter, Sonja (2002), "The Role of Consumers' Trust in Online Shopping," Journal of Business Ethics, 39(1/2), 43-50. 
Griffin, Gill (2002), Customer Loyalty: How to Earn It, How to Keep It, San Francisco: Jossey-Bass.

Gursoy, Dogan and Ken W. McCleary (2004), "An Integrative Model of Tourists' Information Search Behavior," Annals of Tourism Research, 31(2), 353-373.

Hair, J.F., R.E. Anderson, R.L. Tatham, and W.C. Black (1998), Multivariate Data Analysis, 5th Ed. NJ: Prentice-Hall.

Harris, Lloyd C. and Mark M.H. Goods (2004), "The Four Levels of Loyalty and the Pivotal Role of Trust: A Study of Online Service Dynamics," Journal of Retailing, 80(2), 139-158.

Häubl, Gerald and Valerie Trifts (2000), "Consumer Decision Making in Online Shopping Environments: The Effects of Interactive Decision Aids," Marketing Science, 19(1), 4-21.

Hoffman, Donna L. and Thomas P. Novak (1996), "Marketing in Hypermedia Computermediated Environments: Conceptual Foundations," Journal of Marketing, 60(July), 50-68.

Hofstede, Geert (2003), "Cultural Dimensions," available at: www.geer-hofstede.com

Holbrook, Morris B. and Meryl P. Gardner (2000), "Illustrating a Dynamic Model of the Mood-updating Process in Consumer Behavior," Psychology \& Marketing, 17 (3), 165-194.

Huberty, Carl J. (1994), Applied Discriminant
Analysis, NewYork: Wiley-Interscience Publications, NY.

Hyde, Kenneth F. (2008)," Information Processing and Touring Planning Theory," Annals of Tourism Research, 35(3), 712-731. Johnson, Michael D., Eugene W. Anderson, and Claes Fornell (1995), "Rational and Adaptive Performance Expectations in a Customer Satisfaction Framework," Journal of Consumer Research, 21(4), 695-707.

Kau, Ah Keng., Yingchan E. Tang, and Sanjoy Ghose (2003), "Typology of Online Shoppers," Journal of Consumer Marketing, 20(2), 139-156.

Kim, Dae-Young., Xinran Y. Lehto, and Alastair M.Morrison (2007), "Gender Differences in Online Travel Information Search: Implications for Marketing Communications on the Internet," Tourism Management, 28 (2), 423-433.

Kim, Dan J., Donald L. Ferrin, and H. Raghav Rao (2006), "An Investigation of Consumer Online Trust and Purchase-Repurchase Intentions," in Proceedings of the TwentyFourth International Conference on Information Systems, 353-365.

Kim, Hee-Woong., Yunjie Xu, and Joon Koh (2004), “A Comparison of Online Trust Building Factors between Potential Customers and Repeat Customers," Journal of the Association for Information System, 5(10), 392-420.

Kolsaker, Ailsa and Claire Payne (2002), "En- 
gendering Trust in E-commerce: A Study of Gender-based Concerns," Marketing Intelligence \& Planning, 20(4), 206-214.

Kuan, H., G. Bock, and V. Vathanophas (2007), "Comparing the Effects of Website Quality on Consumer Initial Purchase and Continued Purchase at E-commerce Websites," Behaviour \& Information Technology, 25, 1-14.

Lee, Matthew K.O. and Efraim Turban (2001), "A Trust Model for Consumer Internet Shopping," International Journal of Electronic Commerce, 6(1), 75-91.

Li, Nai and Gill Kirkup (2007), "Gender and Cultural Differences in Internet Use: A Study of China and the UK," Computer \& Education, 48(2), 301-317.

Lian, Jiunn-Woei and Tzu-Ming Lin (2008), "Effects of Consumer Characteristics on Their Acceptance of Online Shopping: Comparisons among Different Product Types," Computers in Human Behavior, 24(1), 48-65.

Lynch, Patrick D., Robert J. Kent, and Srini S. Srinivasan (2001), "The Global Internet Shopper: Evidence from Shopping Tasks in Twelve Countries," Journal of Advertising Research, 41(3), 15-23.

Madden, Thomas J., Kelly Hewett, and Martin S. Roth (2000), "Managing Images in Different Cultures: A Cross-national Study of Color Meanings and Preferences," Journal of International Marketing, 8(4), 90-107.
Martin, Brett A.S. (2003), "The Influence of Gender on Mood Effects in Advertising," Psychology \& Marketing, 20(3), 249-273 McKnight, D. Harrison and N.L. Chervany (2002), "What Trust Means in E-commerce Customer Relationships: An Interdisciplinary Conceptual Typology," International Journal of Electronic Commerce, 6(2), 35-59.

Mittal, Vikas and Wagner A. Kamakura (2001), "Satisfaction, Repurchase Intent, and Repurchase Behavior: Investigating the Moderating Effect of Customer Characteristics," Journal of Marketing Research, 38(1), 131-142.

William T. Ross, and Patrick M. Baldasare (1998), "The Asymmetric Impact of Negative and Positive Attribute-Level Performance on Overall Satisfaction and Repurchase Intentionss," Journal of Marketing; 62(1), 33-47.

Moe, Wendy W. (2003), "Buying, Searching, or Browsing: Differentiating between Online Shoppers Using In-store Navigational Clickstream," Journal of Consumer Psychology, 31(1/2), 29-39.

Moschis, George P. (1976), "Shopping Orientations and Consumer Uses of Information," Journal of Retailing, 52(Summer), 61-70.

Mullen, Michael R. (1995), "Diagnosing Measurement Equivalence in Cross-national Research," Journal of International Business Studies, 26, 573-596.

Oliver, Richard L. (1997), Satisfaction: A Be- 
havioral Perspective on the Consumer, NewYork: McGraw-Hill.

Park, Cheol and Jong-Kun Jun (2003), "A Cross-cultural Comparison of Internet Buying Behavior: Effects of Internet Usage, Perceived Risks, and Innovativeness," International Marketing Review, 20(5), 534-553.

Pavlou, Paul A. (2003), "Consumer Acceptance of Electronic Commerce: Integrating Trust and Risk with the Technology Acceptance Model," International Journal of Electronic Commerce, 7(3), 101-134.

Peterson, Robert A. (2001), "On the Use of College Students in Social Science Research: Insights from a Second-order Meta-Analysis," Journal of Consumer Research, 28(December), 450-461. , Sridhar Balasubramanian, and bart J. Bronnenberg (1997), "Exploring the Implications of the Internet for Consumer Marketing," Journal of the Academy of Marketing Science, 25(4), 329-346.

Richins, Marsha L. and S.A. Dawson (1992), "A Consumer Value Orientation for $\mathrm{Ma}^{-}$ terialism and Its Measurement: Scale Development and Validation," Journal of Consumer Research, 19, 303-316.

Rogers, H.P., R.M. Peyton, and R.L. Berl (1992), "Measurement and Evaluation of Satisfaction Processes in a Dyadic," Journal of Consumer Satisfaction, Dissatisfaction, and Complaining Behavior, 5, 12-23.

Rohm, Andrew J. and Vanitha Swaminathan
(2004), “A Typology of Online Shoppers based on Shopping Motivations," Journal of Business Research, 57(7), 748-754.

Ross, Mike (1989), "Relation of Implicit Theories to the Construction of Personal Histories," Psychological Review, 96, 341-357.

Roy, Abhik (1994), "Correlates of Mall Visit Frequency," Journal of Retailing; 70(2), 139-161.

Roy, S. and S. Ghose (2005), "Internet Adoption as a Two-stage Transition: Converting Internet Non-users to Internet Users and to Online Buyers," International Journal of Market Research, 48(3), 321-349.

Rust, Roland T. and Richard L. Oliver (1994), Service Quality: New Directions in Theory and Practice, Sage: Thousand Oaks, 72-94. Schlosser, Ann E., Tiffany Barnett White, and Susan M. Lloyd (2006), "Converting Web Site Visitors into Buyers: How Web Site Investment increases Consumer Trusting Beliefs and Online Purchase Intentions," Journal of Marketing, 70(2), 133-148.

Shankar, Venkatesh., Amy K. Smith, and Arvind Rangaswamy (2003), "Customer Satisfaction and Loyalty in Online and Offline Environments," International Journal of Research in Marketing, 20(2), 153-175. Sheehan, Kim Bartel (1999), “An Investigation of Gender Differences in Online Privacy Concerns and Resultant Behaviour," Journal of Interactive Marketing, 13(4), 24-38.

Shim, Soyeon., Mary Ann Estlick, Sherry L. 
Lotz, and Patricia Warrington (2001), “An Online Prepurchase Intentions Model: The Role of Intention to Search," Journal of Retailing, 77(3), 397-416.

Simintiras, Antonia., Adamantios Diamantopoulos, and Judith Ferriday (1997), "Pre-purchase Satisfaction and First-time Buyer Behaviour: Some Preliminary Evidence," European Journal of Marketing, 31(11/12), 857-872.

Simon, S.J. and S.C. Peppas (2005), “Attitudes towards Product Website Design: A Study of the Effects of Gender," Journal of Marketing Communications, 11(2), 129-144.

Singh, and Sirdeshumkh (2002), "Agency and Trust Mechanism in Consumer Satisfaction and Loyalty Judgments," Journal of the Academy of Marketing Science, 28(1), 150-167. Slyke, C.V., C.L. Comunale, and F. Belanger (2002), "Gender Differences in Perceptions of Web-based Shopping," Communications of the ACM, 45(7), 82-86.

Sorce, Patricia., Victor Perotti, and Stanley Widrick (2005), "Attitude and Age Differences in Online Buying," International Journal of Retail \& Distribution Management, 33(2), 122-132.

Srinivasan, Srini S., Rolph Anderson, and Kishore Ponnavolu (2002), "Customer Loyalty in E-commerce: An Exploration of Its Antecedents and Consequences," Journal of Retailing, 78(1), 41-50.

Steenkamp, Jan-Benedict E. M. and Hans Baumgartner (1998), “Assessing Measurement
Invariance in Cross-national Consumer Research," Journal of Consumer Research, 25(1), 78-90. and Ter

Hofstede, F. (2002), "International Market Segmentation: Issues and Perspectives," International Journal of Research in Marketing, 19(3), 185-213.

Stephenson, R. P. and R.P. Willett (1969), "Analysis of Consumer's Retail Patronage Strategies," In P.R. McDonald (Ed.)., Marketing involvement in society and economy (pp.316-322). Chicago: American Marketing Association.

Stone, G.P. (1954), "City and Urban Identification: Observation on the Social Psychology of City Life," American Journal of Sociology, 60(July), 36-45.

Swaminathan, Vanitha., Elzbieta LepkowskaWhite, and Bharat P. Rao (1999), "Browsers of Buyers in Cyberspace? An Investigation of Factors Influencing Electronic Exchange," Journal of Computer-Mediated Communication, 5(2), availableat: www.jcmc.indiana.edu/ vol5/issue2/swaminathan.htm

Taylor, Steven A. and Gary L. Hunter (2002), "The Impact of Loyalty with E-CRM Software and E-services," International Journal of Service Industry Management, 13(5), 452-478.

Teach, Richard D. and Robert Schwartz (2003), "University Student E-tailing: A Marketing Study at the Entrepreneurship Interface," 
International Journal of Entrepreneurial Behavior \& Research, 9(4), 133-145.

Teo, Hock-Hai., Lih-Bin Oh, ChunhuiLiu, and Kwok-KeeWei (2003), “An Empirical Study of the Effects of Interactivity on Web User Attitude," International Journal of Human-Computer Studies, 58(3), 281-305.

Vishwanath, Arun (2003), “Comparing Online Information Effects: A Cross-cultural Comparison of Online Information and Uncertainty Avoidance," Communication Research, 30(6), 579-598.

Wang, Paul Z. and David S. Waller (2006), "Measuring Consumer Vanity: A Crosscultural Validation," Psychology \& Marketing, 23(8), 665-687.

Wang, Sophia and Waiman Cheung (2004), "E-business Adoption by Travel Agencies: Prime Candidates for Mobile E-business," International Journal of Electronic Commerce, 8(3), 43-63.

Wolf, Alecia (2000), "Emotional Expression Online: Gender Differences in Emotional Use," CyberPsychology \& Behavior, 3(5), 827-833.

Yi, Youjae and Suna La (2004), "What Influences the Relationship between Customer Satisfaction and Repurchase Intention? Investigating the Effects of Adjusted Expectations and
Customer Loyalty," Psychology \& Marketing, 21(5), 351-373.

Yoh, Eunah., Mary Lynn Damhorst, Stephen Sapp, and Russ Laczniaj (2003), "Consumer Adoption of the Internet: The Case of Apparel Shopping," Psychology \& Marketing; 20(12), 1095-1118.

Yoon, Moon Gil., Duk Young Yoon, and Tae Won Yang (2006), "Impact of E-business on Air Travel Markets: Distribution of Airline Tickets in Korea," Journal of Air Transport Management, 12(5), 253-260.

Yoon, Sung-Joon (2002), “The Antecedents and Consequences of Trust in Online-Purchase Decisions," Journal of Interactive Marketing, 16(2), 47-63.

Yu, Chien-Chih and Hsing Wang (2004), "Digital Divide in Taiwan: Evidence, Comparisons, and Strategies," Electronic Government and International Journal, 1(2), 179-197.

Zajonc, Robert B. and Hazel Markus (1982), "Affective and Cognitive Factors in Preferences," Journal of Consumer Research, 9(2), 123-131.

Zhou, Lina., Liwei Dai, and Dongsong Zhang (2007), "Online Shopping Acceptance Model: A Critical Survey of Consumer Factors in Online Shopping," Journal of Electronic Commerce Research, 8(1), 41-62. 


\section{〈Appendix〉}

Information Quality

This website makes purchase recommendations that match my needs.

The website enables me to order products or services that are tailor-made for me.

I believe that this website is customized to my needs.

Commercials must have instant appeal in providing the usefulness of the brand.

*This commercial was very informative.

Reading/watching advertisements regularly to compare competing websites is essential.

*Customers must share experiences concerning the product or service information with other customers of the website.

\section{Satisfaction}

I am satisfied with this website.

This website offers what I expect from a good website.

This website gives me a feeling of satisfaction.

I think that I made the correct decision to use this website.

Trust

I think that this website usually fulfils the commitments it assumes.

This website does not make false statements.

I think that this website has sufficient experience in the marketing of the products and services that it offers.

Most of what this website says about its products or services is true.

I think that information offered by this site is sincere and honest.

\section{Attitudes toward a particular website}

This website makes it easy for me to build a relationship with this company.

I would like to visit this website again in the future.

I feel comfortable in surfing this website.

I feel surfing this website is a good way for me to spend time.

Compared with other website, I would rate this one as (one one as (est-one of the worst).

Note: * was eliminated at the final stage. 